Article

\title{
Effect of Carbon Fiber Addition on the Microstructure and Wear Resistance of Laser Cladding Composite Coatings
}

\author{
Jianfeng Li ${ }^{1,2}$, Zhencai Zhu ${ }^{1,2, *}$, Yuxing Peng ${ }^{1,2}$ and Gang Shen ${ }^{1,2}$ \\ 1 School of Mechanical and Electrical Engineering, China University of Mining and Technology, University \\ Road, Quanshan District, Xuzhou 221116, China; ljfcumt@126.com (J.L.); pengyuxingcumt@126.com (Y.P.); \\ shenganghit@163.com (G.S.) \\ 2 Jiangsu Key Laboratory of Mine Mechanical and Electrical Equipment, China University of Mining and \\ Technology, Xuzhou 221116, China \\ * Correspondence: zhuzhencai@cumt.edu.cn
}

Received: 18 September 2019; Accepted: 16 October 2019; Published: 20 October 2019

\begin{abstract}
In this study, the effect of carbon fibers (CFs) on the microstructure and wear resistance of Fe-based alloy coating produced by laser cladding was investigated by X-ray diffractometer (XRD), scanning electron microscopy (SEM), energy-dispersive spectrometer (EDS), and wear tester. The results indicated that with the addition of $\mathrm{CFs}$, the microstructure of the composite coating mainly transformed from $\alpha$-Fe cellular dendrites and $\gamma-\mathrm{Fe} /(\mathrm{Cr}, \mathrm{Fe})_{7} \mathrm{C}_{3} / \mathrm{CrB}$ eutectics to bulk-like $(\mathrm{Cr}, \mathrm{Fe})_{7} \mathrm{C}_{3}$, nano-size $\mathrm{B}_{4} \mathrm{C}$, and $\gamma-(\mathrm{Fe}, \mathrm{Ni}) /(\mathrm{Cr}, \mathrm{Fe})_{23} \mathrm{C}_{6}$ lamellar eutectics. Additionally, the microhardness and wear resistance of the composite coating compared with the original coating both increased by approximately two times. The original coating showed the dominant wear mechanisms of micro-cutting and serious brittle spalling, while the composite coating with CFs showed the main wear mechanism of slight scratching.
\end{abstract}

Keywords: $\mathrm{CFs}$; laser cladding; $(\mathrm{Cr}, \mathrm{Fe})_{7} \mathrm{C}_{3} ; \mathrm{B}_{4} \mathrm{C}$; wear resistance

\section{Introduction}

$16 \mathrm{Mn}$ steel, high-strength low-alloy steels, show appropriate strength and toughness, allowable design stress, and reasonable economy; thus, it has been extensively used in the manufacture of mining machines, transportation equipment, and in the chemical industry, etc. However, its weak properties, including low hardness and poor anti-wear abilities, fail to satisfy requirements during service thereby restricting its wide applications in many fields. Surface modification technologies, such as plasma cladding, laser alloying, selective laser melting, and laser cladding, have produced hard coatings on the surface of steel substrates, and this is considered to be one of the most practical solutions. This not only ensures that the conventional steel parts show high surface hardness and wear resistance, but also simultaneously provides considerable commercial benefits [1,2].

Laser cladding (LC) has been widely applied in the modification of surface properties with an improved wear resistance instead of other surface modification technologies [3-8]. Some of the advantages of LC, such as high efficiency, minimal dilution ration, high bonding strength, refined microstructure, and excellent properties, are difficult to obtain using other surface modification techniques $[9,10]$. Over the last few years, many former researchers have devoted themselves to the preparation of composite coatings using various reinforcements. For instance, Han et al. [11] reported using laser cladding coatings fabricated on a $35 \mathrm{CrMo}$ steel surface with cladding materials composed of $\mathrm{Fe}$ and $\mathrm{Cr}_{3} \mathrm{C}_{2}$, and the results showed that the hardness and wear resistance of the coatings enhanced markedly with the increase of $\mathrm{Cr}_{3} \mathrm{C}_{2}$ content. Guo et al. [12] fabricated $\mathrm{ZrB}_{2}$ reinforced Ni-based 
composite coatings on a Ti substrate, and the formation of $\mathrm{ZrB}_{2}$ increased the wear resistance of the substrate by about four times. Yang et al. [13] investigated that the hardness and anti-wear capabilities of laser cladding TiCN/Ti composite coatings. Both the hardness and anti-wear capabilities of the $\mathrm{TiCN} / \mathrm{Ti}$ coating were highly superior to the Ti-6Al-4V substrate. Although the hardness and wear resistance of metal-based coatings could further be improved by in-situ formed hard phases, there also existed several defects in the resultant components. For example, stress concentration was caused by the particles' sharpness; the plastic and toughness of the coatings were decreased due to the particles' dissolution at the high-temperature molten pool. Hence, extensive endeavors have been made to search for other reinforcing phases possessing better properties. The CFs possessed high specific strength, thermal conductivity, anti-corrosion, high modulus, etc. CFs also possessed as self-lubricating property, which was recognized as an ideal reinforcement [14], beneficial for the antifriction capacity of the composites.

Hence, in the present research, a detailed study on the effect of the microstructure and wear resistance of the composite coating was conducted, and wear mechanisms were further analyzed.

\section{Experimental Procedures}

\subsection{Preparation of Composite Coatings}

$16 \mathrm{Mn}$ steels, with dimensions of $100 \mathrm{~mm} \times 40 \mathrm{~mm} \times 8 \mathrm{~mm}$, were adopted for the substrate, which had surfaces that were mechanically abraded with stand paper followed by rinsing ultrasonically with acetone to remove the contaminants before the cladding process. Chemical compositions of the substrate and Fe-based alloy powders (Fe60) are summarized in Table 1. Iron-based alloy powders and $\mathrm{CFs}$ were employed as the matrix material and additives, respectively. The Fe60 alloy powders with 0 $\mathrm{wt} . \%$ and $5 \mathrm{wt} . \%$ of CFs were homogeneously mixed in planetary ball mill for the preparation of the composite powders, respectively. Figure 1 shows the morphologies of the Fe60 and Fe60/CF powder mixtures. The diameter of Fe60 was approximately $100 \mu \mathrm{m}$. In addition, CFs with an approximately $10 \mu \mathrm{m}$ diameter and $75 \mu \mathrm{m}$ length were observed. As can be seen in Figure 1b, the spherical particles are pure Fe60 alloy powders and the rod-like particles are carbon fibers. The Fe60 alloy powders and $\mathrm{CFs}$ were homogeneity mixed. Before laser cladding, the mixed powders were heated in a resistance furnace at $60^{\circ} \mathrm{C}$ for $5 \mathrm{~h}$ to eliminate the oxide skin. Then, the precursor mixtures of Fe60 alloy powders and CFs were directly preplaced on the substrate surfaces, with the powder bed thickness of $1.5 \mathrm{~mm}$.

Table 1. The chemical composition of the $16 \mathrm{Mn}$ substrate and Fe60 alloy powder (in wt.\%).

\begin{tabular}{ccccccccccc}
\hline Material & Fe & Mn & Ni & Cr & $\mathbf{C}$ & Si & Cu & P & S & B \\
\hline $16 \mathrm{Mn}$ & Bal. & $1.2-1.6$ & $\leq 0.3$ & $\leq 0.3$ & $0.1-0.2$ & $0.2-0.6$ & $\leq 0.25$ & $\leq 0.03$ & $\leq 0.03$ & - \\
Fe60 & Bal. & - & $0.1-1$ & $13-17$ & $0.5-1.0$ & $0.3-1.0$ & - & - & - & $0.2-1.5$ \\
\hline
\end{tabular}

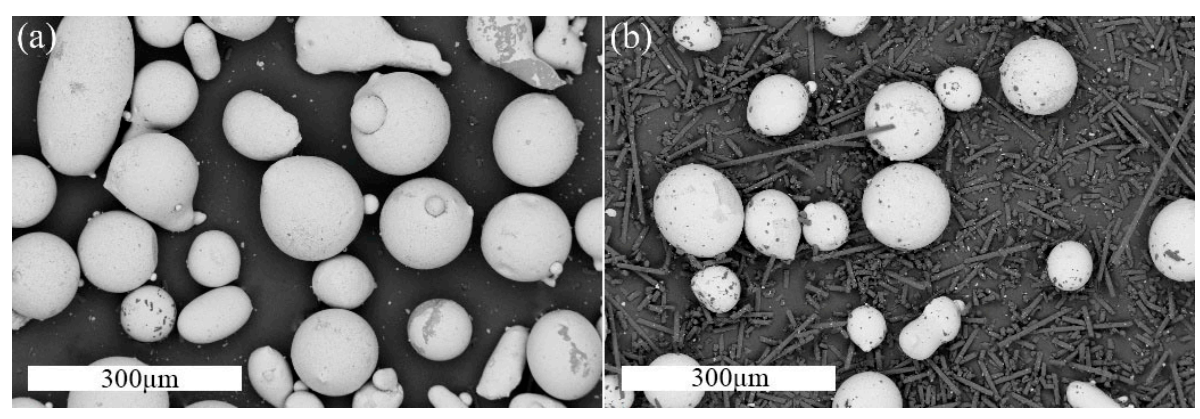

Figure 1. The morphologies of the Fe60 (a) and Fe60/CFs powder mixtures (b).

After that, a Laserline laser cladding system (LDF4000-100, Redmond, WA, USA), a high-power continuous-wave semiconductor laser with a wavelength of $980 \mathrm{~nm}$, was used for laser cladding in 
this investigation. The laser beam was adjusted into a rectangle laser spot with size of $12 \mathrm{~mm} \times 3 \mathrm{~mm}$ by a $100 \mathrm{~mm}$ optical lens. Table 2 lists the suitable processing parameters. The schematic diagram of the laser cladding process is shown in Figure 2a.

Table 2. The laser process parameters and preplaced powder compositions in this study.

\begin{tabular}{ccccc}
\hline Number & Composition (wt. $\%)$ & Power $(\mathrm{KW})$ & Scanning Speed $(\mathbf{m m} / \mathbf{s})$ & Overlapping Rate $(\%)$ \\
\hline Coating 1 & Fe60 & 4.0 & 6 & \multirow{2}{*}{30} \\
Coating 2 & Fe60/5CFs & 4.0 & & \\
\hline
\end{tabular}

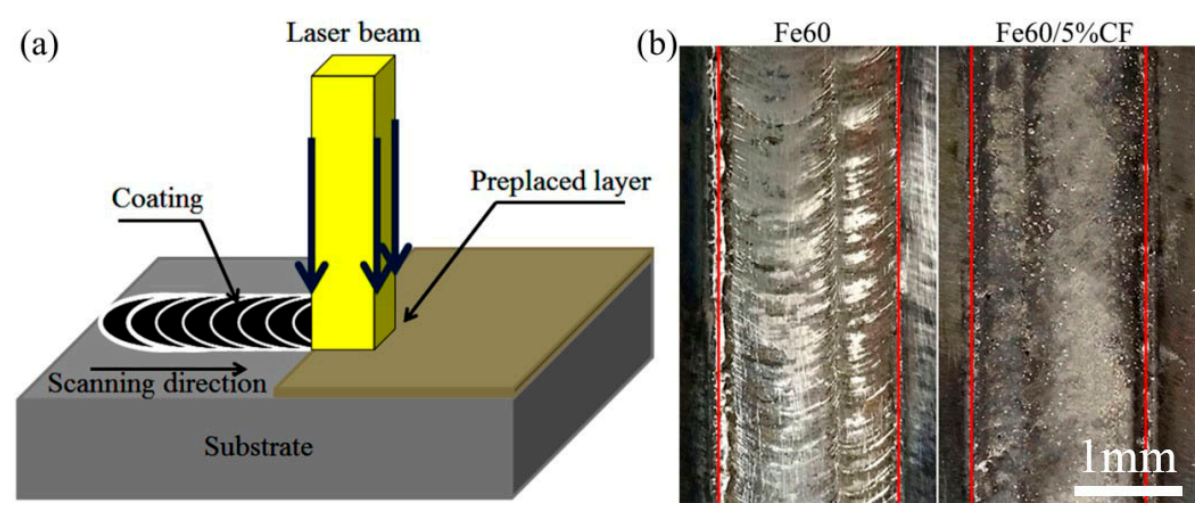

Figure 2. (a) The schematic diagram of the laser cladding process; (b) the surface morphologies of Coating 1 and Coating 2.

\subsection{Microstructure Characterization and Properties Measurements}

The cross-sections of cladded samples were abraded, then polished, and finally etched with a mixed solution of alcohol- 5 vol. $\% \mathrm{HNO}_{3}$. The etching time was around $30 \mathrm{~s}$. The microstructure and the chemical compositions were identified with the assistance of an optical electron microscope (Sigma, ZEISS, Oberkochen, Germany), scanning electron microscope (Sigma, ZEISS Merlin Compact, Oberkochen, Germany), energy-dispersive spectrometer (EDS, ZEISS, Oberkochen, Germany), as well as an X-ray diffractometer (D8 Advance, Bruker, Billerica, MA, USA). The element states of the Fe60/CF alloy coating were analyzed by X-ray photoelectron spectrometer (XPS, ESCALAB 250XL, Thermo, Waltham, MA, USA).

The microhardness distribution from the coating surface to the substrate was measured via a Vickers hardness tester (THV-5MD) with a $5 \mathrm{~N}$ test load and $10 \mathrm{~s}$ holding time. The dry friction and wear properties of the cladding coatings were conducted by "ball-on-disk" UMT-2 tribo-meter (CETR, Bruker, Billerica, USA). The upper counterpart was an $\mathrm{Al}_{2} \mathrm{O}_{3}$ ceramic ball with a hardness of over HRC95 with a diameter of $10 \mathrm{~mm}$. The as-prepared coatings were used as lower specimens. The testing parameters included: the applied loads of $30 \mathrm{~N}$, the linear velocity of $10 \mathrm{~mm} / \mathrm{s}$, and the wear test cycle of $60 \mathrm{~min}$. The wear mass loss after the sliding tests was measured at an interval of $15 \mathrm{~min}$ using a precision analytical balance with a minimum scale value of $0.1 \mathrm{mg}$. Additionally, to minimize the resulting deviation, all wear tests were conducted three times. The wear resistance of the coatings was evaluated using the average value of the mass loss. The wear mechanism of the cladding coating was further investigated with the assistance of SEM characterization.

\section{Results and Discussion}

\subsection{Macro Observation}

Figure $2 \mathrm{~b}$ shows the surface macro morphologies of Coating 1 and Coating 2 . The surface of coating 1 showed the metallic luster with smoothness, while coating 2 had a relatively dark surface which was much coarser. The reason might be that the addition of CFs changed the composition of 
the molten pool, which facilitated the occurrence of more complicated and violent chemical reactions during laser cladding. Figure 3 shows the cross-section morphologies of Coating 1 and Coating 2 . As shown, both composite coatings showed the dense and defect-free metallurgical bonding with the substrate while Coating 2 had a thicker thickness than Coating 1 . The reason was probably that CFs had high absorption of the laser beam that allowed for the obtention of more heat energy due to the high absorptivity of carbon, promoting an increasing amount of the substrate to be melted and mixed with molten cladding material which reasonably facilitated the formation of the coating with higher dilution ratio and thicker thickness [15-17]. In addition, there existed several big, black points in Coating 2, and these points are attributed to outside dust rather than CF conglomerates or pores, according to the SEM results shown in Figure 4.

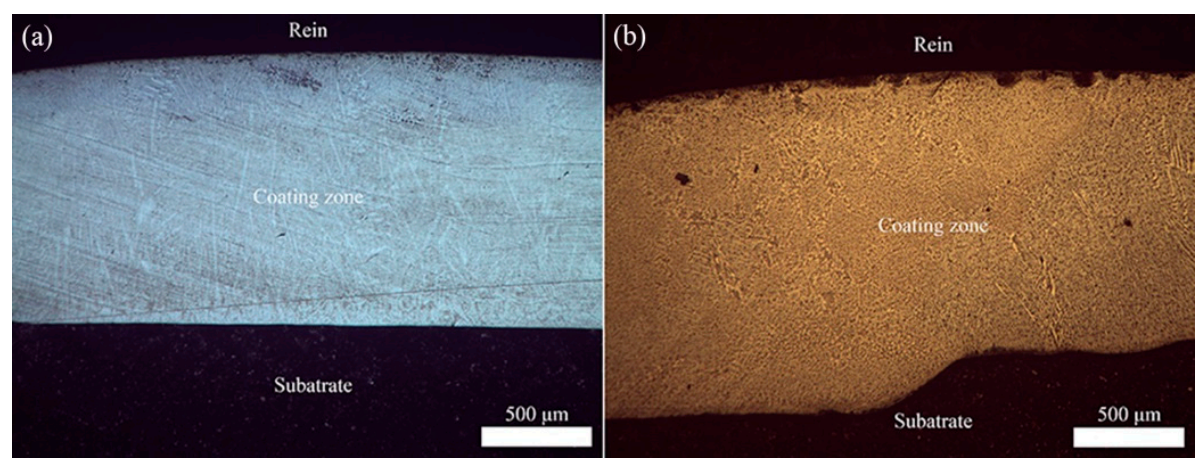

Figure 3. Cross-section morphologies of (a) Coating 1 and (b) Coating 2.

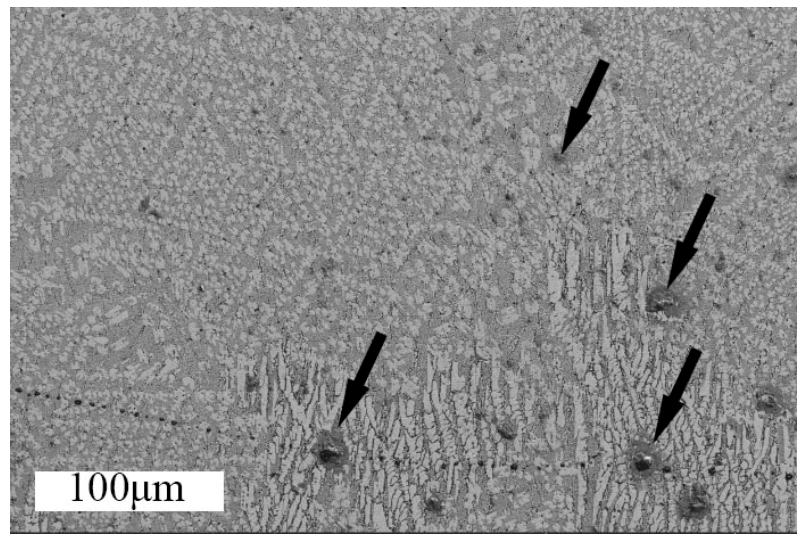

Figure 4. SEM images of black points in Coating 2.

\subsection{Microstructure}

The microstructural characteristics of the composite coatings are presented in Figure 5. As shown, the microstructural morphologies of both composite coatings presented apparent differences. As shown in Figure $5 \mathrm{a}, \mathrm{d}$, it was found that planar crystals formed at the interface between the composite coating and the substrate, and the thickness of the planar crystal formed in Coating 1 and Coating 2 was approximately 10 and $50 \mu \mathrm{m}$, respectively. Obviously, the thickness of the planar crystal formed in Coating 1 was larger than that formed in Coating 2; this evidently indicates that a better interface metallurgical bonding between the substrate and the composite coating was obtained with the addition of CFs. Furthermore, the microstructure of Coating 2 differed completely from that of Coating 1 . Due to the fact that the optical microscopy could not clearly observe the microstructure, further SEM analysis was performed, and the images are shown in Figure 6. 


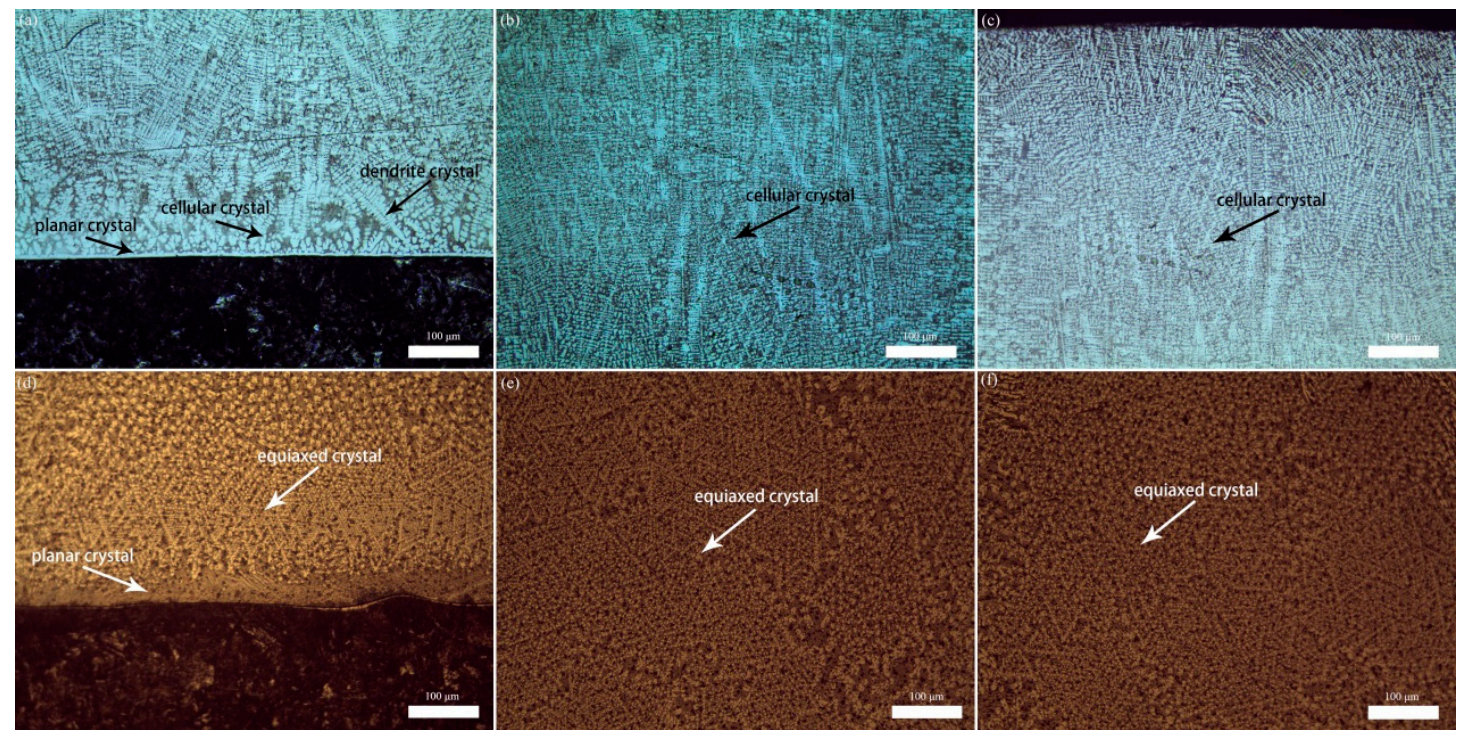

Figure 5. (a-c) Bottom, middle, and upper region of Coating 1 and (d-f) bottom, middle, and upper region of Coating 2.

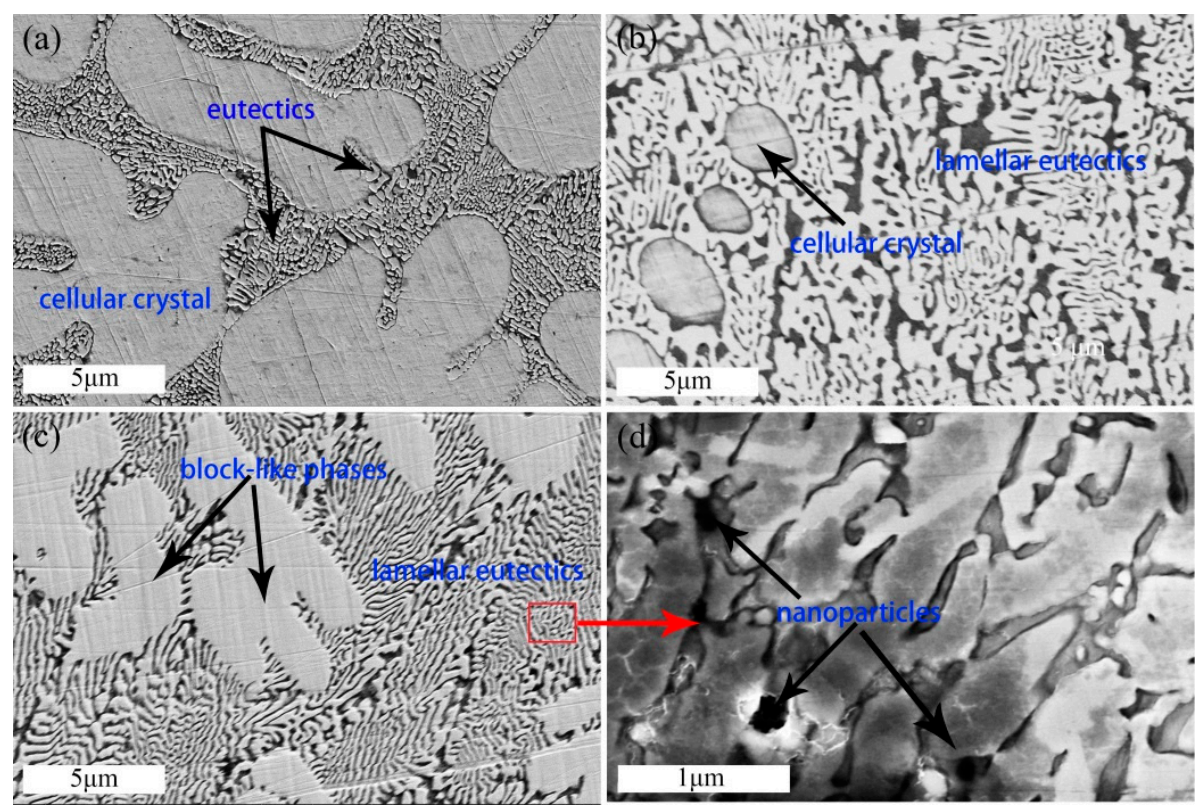

Figure 6. SEM micrographs of the different regions of Coating 1 and Coating 2: (a) middle region of Coating $1 ;(\mathbf{b}, \mathbf{c})$ bottom region and top region of Coating $2 ;(\mathbf{d})$ high magnification of lamellar eutectics.

The microstructure of Coating 1 did not change significantly with the distance from the bottom to upper region. Figure 6a shows SEM images of Coating 1. As shown, Coating 1 mainly consisted of two different kinds of phases which were cellular crystals and eutectics in respect to the bottom and upper regions. On the contrary, for Coating 2, the microstructure of the middle region was similar to that of upper region, but the bottom region showed different microstructure. Obviously, the bottom region of Coating 2 consisted of cellular crystals and eutectics, while the middle and upper regions were made up of block-like phases, lamellar eutectics, and nanoparticles, as shown in Figure 6b,c.

\subsection{Phase Analysis}

Figure 7 shows the $X$-ray diffraction patterns of the composite coatings. As indicated, $\alpha$-Fe, $\gamma$-Fe, $(\mathrm{Cr}, \mathrm{Fe})_{7} \mathrm{C}_{3}$, and $\mathrm{CrB}$ existed in Coating 1 . However, for Coating $2, \alpha-\mathrm{Fe}, \gamma-\mathrm{Fe},(\mathrm{Cr}, \mathrm{Fe})_{7} \mathrm{C}_{3},(\mathrm{Cr}, \mathrm{Fe})_{23} \mathrm{C}_{6}$, $\mathrm{B}_{4} \mathrm{C}$, and $\mathrm{CFs}$ were found, but the diffraction peaks of $\mathrm{CrB}$ were neglected. Also, compared with 
Coating 1, the peak strengths of $\gamma$-Fe and $\alpha$-Fe in coating 2 increased and decreased, respectively, suggesting that with CFs addition, the content of $\gamma$-Fe and $\alpha$-Fe existing in the composite coating increased and decreased, respectively. Above these phenomena indicated that the phase composition of the composite coating changed with the CFs addition. Some researchers reported [18] that the chemical stability of $\gamma$-Fe increased when more carbon elements were dissolved in austenite during laser cladding. As a result, more $\gamma$-Fe in coating 2 were maintained. Additionally, the diffraction peak of CFs was detected in the composite coating as well, which was due to its incomplete dissolution in the melted pool during laser cladding. The remaining CFs could act as lubricants that played a positive role in the wear resistance. $(\mathrm{Cr}, \mathrm{Fe})_{7} \mathrm{C}_{3}$ and $\mathrm{B}_{4} \mathrm{C}$ carbides could be formed, which resulted from the high affinity between $C r, B$ and $C$ atoms. The standard Gibbs free energy of $\mathrm{Cr}_{7} \mathrm{C}_{3}, \mathrm{Cr}_{23} \mathrm{C}_{6}$, $\mathrm{CrB}$ and $\mathrm{B}_{4} \mathrm{C}$ was shown in Figure 7 . The calculated values of Gibbs free energy $\left(\Delta G_{0}\right)$ of all reactants with the temperature were negative. Hence, $\mathrm{CrB},(\mathrm{Cr}, \mathrm{Fe})_{23} \mathrm{C}_{6},(\mathrm{Cr}, \mathrm{Fe})_{7} \mathrm{C}_{3}$ and $\mathrm{B}_{4} \mathrm{C}$ carbides could form spontaneously. From the thermodynamics perspective, the Gibbs free energy of $(\mathrm{Cr}, \mathrm{Fe})_{23} \mathrm{C}_{6}$ was lower than that of $(\mathrm{Cr}, \mathrm{Fe})_{7} \mathrm{C}_{3}$ in all the ranges of reaction temperature, suggesting that $(\mathrm{Cr}, \mathrm{Fe})_{23} \mathrm{C}_{6}$ compared with $(\mathrm{Cr}, \mathrm{Fe})_{7} \mathrm{C}_{3}$ was more stable and easier to form. However, it was observed that $(\mathrm{Cr}$, $\mathrm{Fe})_{7} \mathrm{C}_{3}$ carbides were main phases of the composite coating in the present study rather than $(\mathrm{Cr}, \mathrm{Fe})_{7} \mathrm{C}_{3}$, which might be attributed to high concentration of $C$ atoms [19]. Ma et al. [20] also reported that dynamics factors such as concentration and activity of solute atoms also affected the formation priority of various phases. Also, as stated above, with $\mathrm{CFs}$ addition, $\mathrm{CrB}$ would not be formed in the composite coating. In fact, the affinity of $\mathrm{Cr}$ and $\mathrm{C}$ was much higher than that of $\mathrm{Cr}$ and $\mathrm{B}$. It was reasonable that $\mathrm{Cr}$ tends to firstly combine with $\mathrm{C}$ atoms to form $\mathrm{Cr}_{7} \mathrm{C}_{3}$ which consumed lots of free $\mathrm{Cr}$ atoms. Therefore, remaining $\mathrm{Cr}$ content in the melt pool was so low as to not react with $\mathrm{B}$ to form $\mathrm{CrB}$.
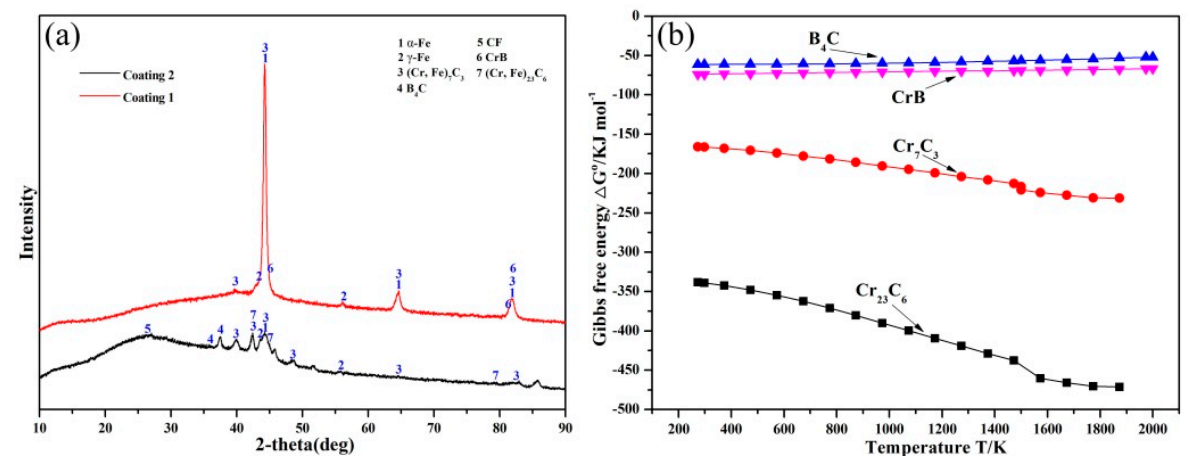

Figure 7. XRD patterns of the composite coatings (a) and the Ellingham diagram of Gibbs free energy via the reaction temperature $(\mathbf{b})$.

The EDS analysis of corresponding phases is listed in Table 3. And elemental distributions of the microstructure of Coating 1 and Coating 2 are shown in Figures 8 and 9, respectively. Combining the $\mathrm{XRD}$ results, it can be deduced that cellular crystals containing a high concentration of $\mathrm{Fe}$, as well as relatively low amounts of $\mathrm{Cr}$ and $\mathrm{C}$, are identifiable as $\alpha$-Fe which belong to a typical supersaturated solid solution; the eutectics mainly consisted of $\mathrm{Fe}, \mathrm{Cr}, \mathrm{C}$, and $\mathrm{B}$ elements, which should be $\gamma-\mathrm{Fe} /(\mathrm{Cr}$, $\mathrm{Fe})_{7} \mathrm{C}_{3} / \mathrm{CrB}$; block-like phases, rich in $\mathrm{Cr}$, $\mathrm{Fe}$, and $\mathrm{C}$ elements, were confirmed as $(\mathrm{Cr}, \mathrm{Fe})_{7} \mathrm{C}_{3}$; lamellar eutectics are mainly rich in $\mathrm{Fe}, \mathrm{Cr}$, and $\mathrm{C}$ which were supposed as $\gamma$ - $\mathrm{Fe} /(\mathrm{Cr}, \mathrm{Fe})_{23} \mathrm{C}_{6}$; nanoparticles mainly contained $\mathrm{B}$ and $\mathrm{C}$ elements which were considered to be $\mathrm{B}_{4} \mathrm{C}$. The XPS of Coating 2 was used to characterize the phase constitution, as shown in Figure 10. The $\mathrm{Cr} 1 \mathrm{~s}$ spectrum contained two wide peaks. One peak had a binding energy of about $573.8 \mathrm{eV}$, which was characteristic for $\mathrm{Cr}-\mathrm{C}$ bonds in $\mathrm{Cr}_{7} \mathrm{C}_{3}$ [21]. Another peak at $575.6 \mathrm{eV}$ might be associated with $\mathrm{Cr}_{2} \mathrm{O}_{3}$ due to the reaction between $\mathrm{Cr}$ and $\mathrm{O}_{2}$. A low amount of oxygen was introduced into the molten pool due to the molten pool not being protected sufficiently by argon and the alloy element $\mathrm{Cr}$ combining with oxygen to form $\mathrm{Cr}_{2} \mathrm{O}_{3}$. Although argon effectively protects the molten pool during laser cladding, a very small amount of air is inevitably introduced into the molten pool as well. Thus, it can well explain the source of the oxygen. 
The B 1s spectrum appeared as two peaks, which at approximately 187.9 and $192 \mathrm{eV}$, it can be assigned to $\mathrm{B}_{4} \mathrm{C}$ and $\mathrm{BCO}_{2}$ [22], respectively. Similarly, The $\mathrm{C}$ 1s spectrum could be resolved into four binding energy peaks. The main peak located at $282.6 \mathrm{eV}$, responsible for $\mathrm{B}-\mathrm{C}$ bonds in $\mathrm{B}_{4} \mathrm{C}$, also further confirmed the existence of $\mathrm{B}_{4} \mathrm{C}$. The other peaks at about $284.5,287.8$, and $288.9 \mathrm{eV}$, respectively, can be characteristic for $\mathrm{C}-\mathrm{C} / \mathrm{C}=\mathrm{C}, \mathrm{C}-\mathrm{O}$, and $\mathrm{O}-\mathrm{C}=\mathrm{O}$ bonds in $\mathrm{CFs}$. Therefore, the presence of $\mathrm{CFs},(\mathrm{Cr}$, $\mathrm{Fe})_{7} \mathrm{C}_{3}$, and $\mathrm{B}_{4} \mathrm{C}$ was further determined.

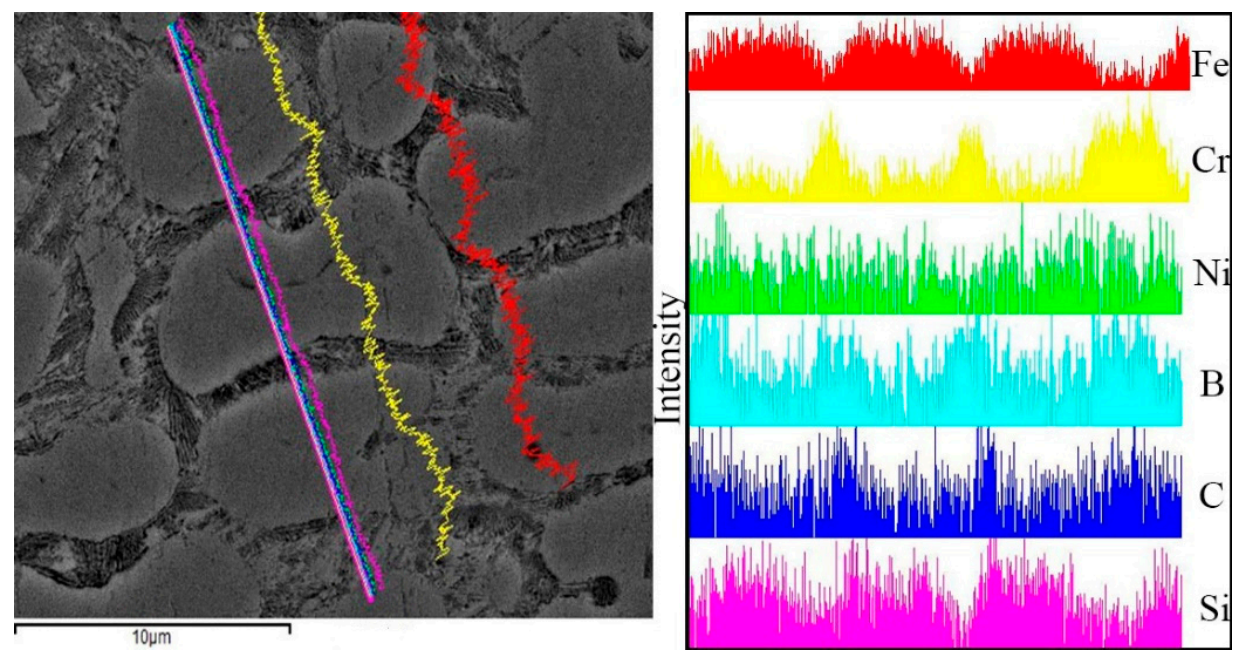

Figure 8. Linear elemental distributions of the microstructure of Coating 1.
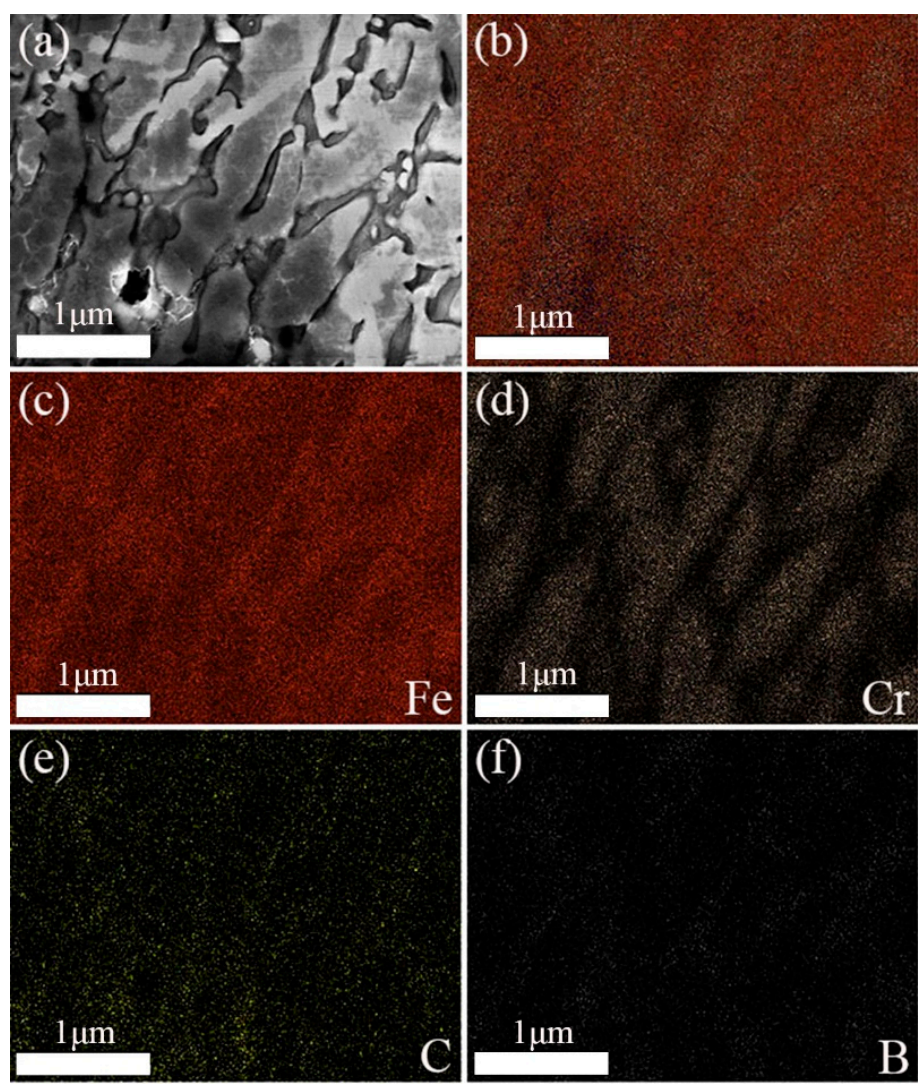

$\mu \mathrm{m}$

Figure 9. The elemental distributions of Coating 2: (b) the element distribution where all elements exist; (c-f) the element distribution of $\mathrm{Fe}, \mathrm{Cr}, \mathrm{C}$, and B elements. 
Table 3. Chemical composition of different phases examined by EDS (at.\%).

\begin{tabular}{ccccccc}
\hline Phase & Fe & Ni & Cr & C & Si & B \\
\hline Cellular crystal & 76.92 & 0.34 & 14.81 & 6.44 & 1.46 & 0.04 \\
Eutectics & 66.80 & 0.37 & 19.18 & 7.16 & 0.75 & 5.74 \\
Block-like phases & 64.92 & 0.35 & 16.98 & 17.62 & 0.09 & 0.03 \\
Lamellar eutectics & 62.91 & 0.31 & 10.10 & 24.43 & 0.64 & 1.61 \\
Nanoparticles & 33.58 & 0.16 & 5.80 & 19.37 & 0.49 & 40.61 \\
\hline
\end{tabular}
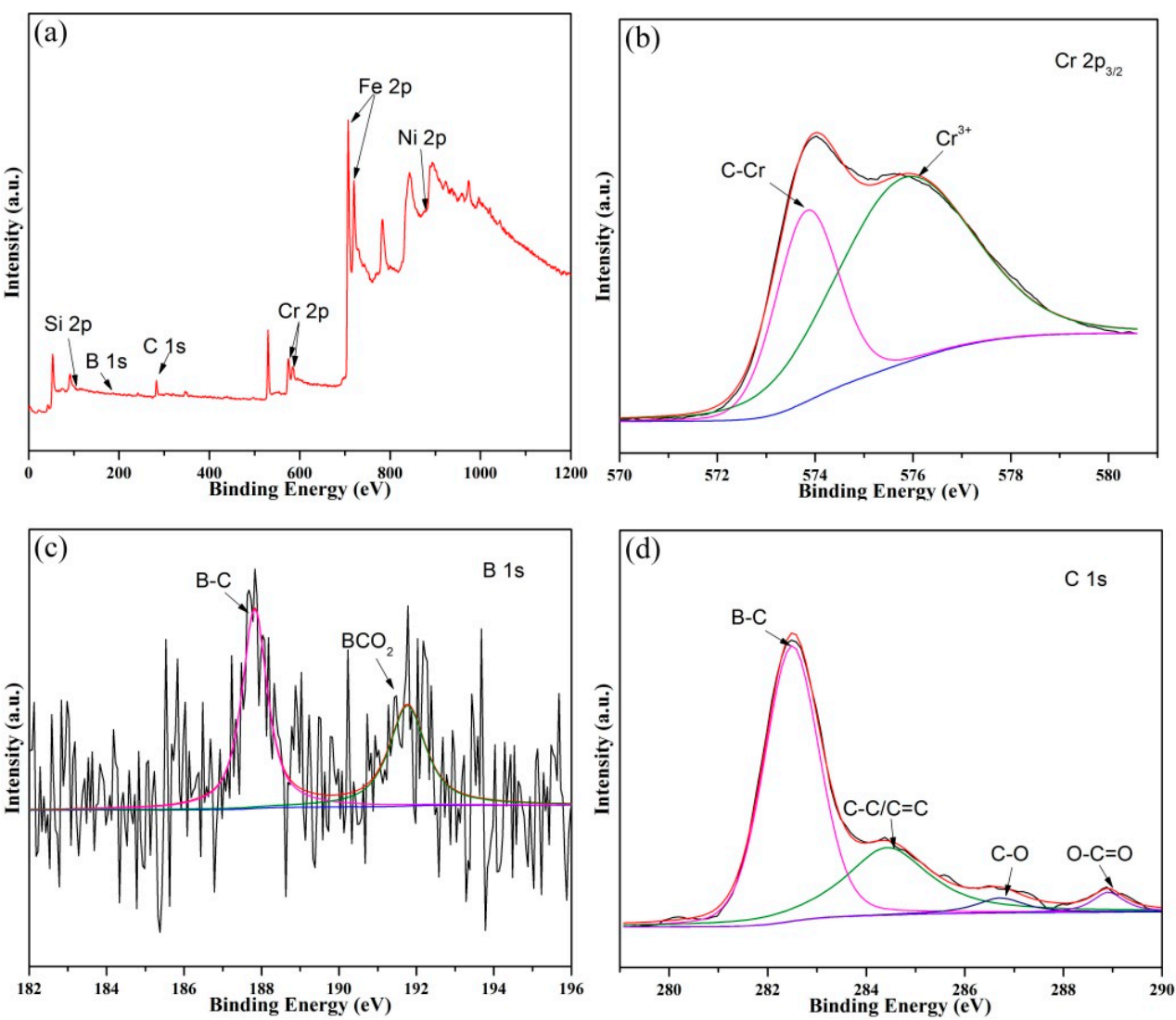

Figure 10. X-ray photoelectron spectra of Coating 2 (a), Cr $2 p(\mathbf{b}), \mathrm{B} 1 \mathrm{~s}$ (c), and C $1 s$ (d).

\subsection{Microstructural Evolution of the Composite Coating with the Addition of CFs}

The solidification process at the bottom was quite different with the top of the cladding coating. The segregation and diffusion of solute atoms, such as $\mathrm{Cr}$ and $\mathrm{C}$, determined the microstructural evolution in the coatings. At the beginning of solidification, there was a great temperature gradient at the substrate-coating interface, and the liquid composition was uniform without any constitutional supercooling [23,24]. Thus, the planar crystal grew along the interface. Iron atoms coming from the substrate entered into the coating zone and CFs with a low density floated which diluted the bottom zone, leading to the low concentration of solute atoms such as $\mathrm{Cr}$ and $\mathrm{C}$ atoms in this region and which was insufficient for carbides nucleation. With the temperature further decreasing, eutectic reaction took place at lower temperature. As a result, the microstructure at the bottom of the cladding coating transformed into a lamellar eutectic structure, as shown in Figure $6 \mathrm{~b}$.

The solidification process was quite different at the upper zone of the cladding coating. Coating surfaces were directly irradiated by the laser beam, leading to a high increase of temperature. A massive number of CFs were dissolved resulting in a significant increase in $\mathrm{C}$ atoms in this region which was sufficient for carbides nucleation. When solidification started, the $(\mathrm{Cr}, \mathrm{Fe})_{7} \mathrm{C}_{3}$ carbides were primarily separated out in the liquid metal. As the chemical composition of the remaining liquid metal 
reached the eutectic point, a eutectic reaction would take place and $\gamma$ - $\mathrm{Fe} /(\mathrm{Cr}, \mathrm{Fe})_{23} \mathrm{C}_{6}$ lamellar eutectics nucleated and grew by attaching on the early precipitated $(\mathrm{Cr}, \mathrm{Fe})_{7} \mathrm{C}_{3}$ carbides, as shown in Figure $6 \mathrm{c}$. The $\gamma-\mathrm{Fe} /(\mathrm{Cr}, \mathrm{Fe})_{23} \mathrm{C}_{6}$ lamellar eutectics could effectively make $(\mathrm{Cr}, \mathrm{Fe})_{7} \mathrm{C}_{3}$ carbides separate. Finally, $(\mathrm{Cr}, \mathrm{Fe})_{7} \mathrm{C}_{3}$ block carbides distributed uniformly among the $\gamma-\mathrm{Fe} /(\mathrm{Cr}, \mathrm{Fe})_{23} \mathrm{C}_{6}$ lamellar eutectics when solidification accomplished. Figure 11 shows the particle size distribution of $\alpha$-Fe cellular crystals in Coating 1 and $(\mathrm{Cr}, \mathrm{Fe})_{7} \mathrm{C}_{3}$ blocks in Coating 2. It was clearly observed that the particle size of $\alpha$-Fe cellular crystals in Coating 1 was a little larger than that of $(\mathrm{Cr}, \mathrm{Fe})_{7} \mathrm{C}_{3}$ blocks in Coating 2. According to the traditional Hall-Petch relationship, fine grain size was also a favorable factor which increased the microhardness and wear resistance. The microhardness and wear resistance of the composite coating with and without $\mathrm{CF}$ s were discussed later.

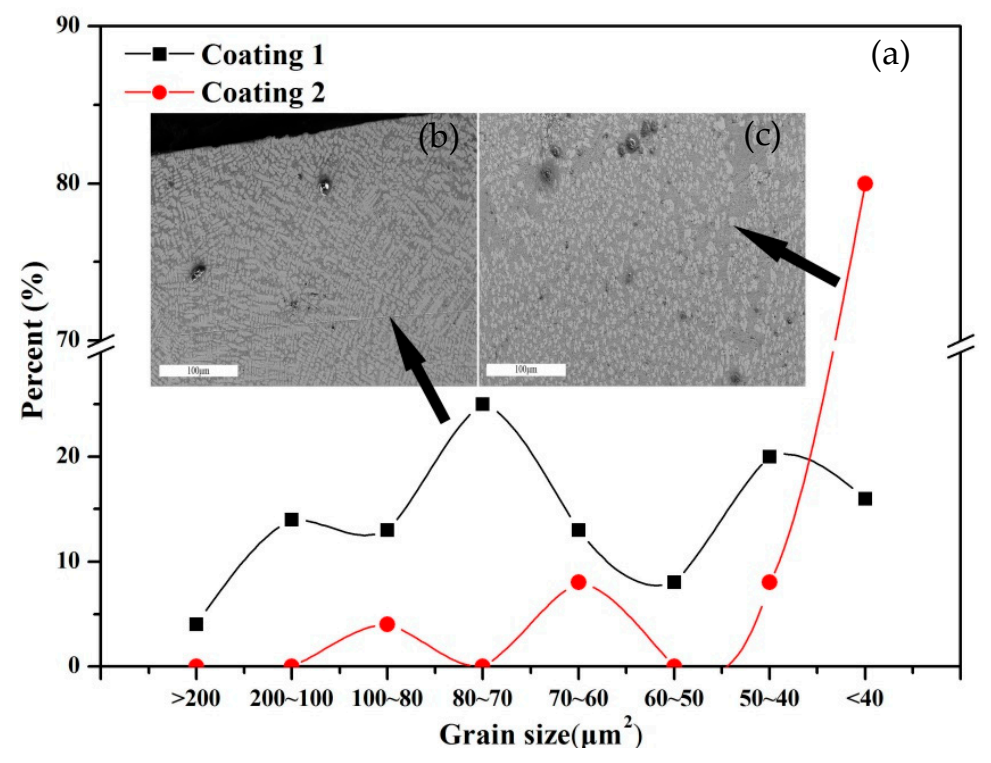

Figure 11. (a) The particle size distribution of $\alpha$-Fe cellular crystals in Coating 1 and $(\mathrm{Cr}, \mathrm{Fe})_{7} \mathrm{C}_{3}$ blocks in Coating 2, (b) $\alpha$-Fe cellular crystals in Coating 1 and (c) $(\mathrm{Cr}, \mathrm{Fe})_{7} \mathrm{C}_{3}$ blocks in Coating 2.

\subsection{Microhardness and Wear Resistance}

Figure 12 illustrates the microhardness profiles of a transverse cross-section of the composite coatings. Obviously, it can be seen that the profile was divided into three regions: coating zone (CZ), heat-affected zone (HAZ), and the substrate (SUB). Both composite coatings showed a similar microhardness distribution, that is, higher in the coating zone and decreasing until the substrate. Differently, the average microhardness of Coating 1 (about $\left.847 \mathrm{HV}_{0.3}\right)$ was much higher than that of Coating 1 (about $457 \mathrm{HV}_{0.3}$ ), which suggests that the microhardness of the composite coating was enhanced with the CFs addition. The hardening mechanism was changed, which mainly transformed from the solid-solution strengthening of supersaturated solid solutions to the dispersion strengthening of in-situ synthesized reinforcements. As stated earlier, the finer grain size of the composite coating with CFs contributed to the higher microhardness. 


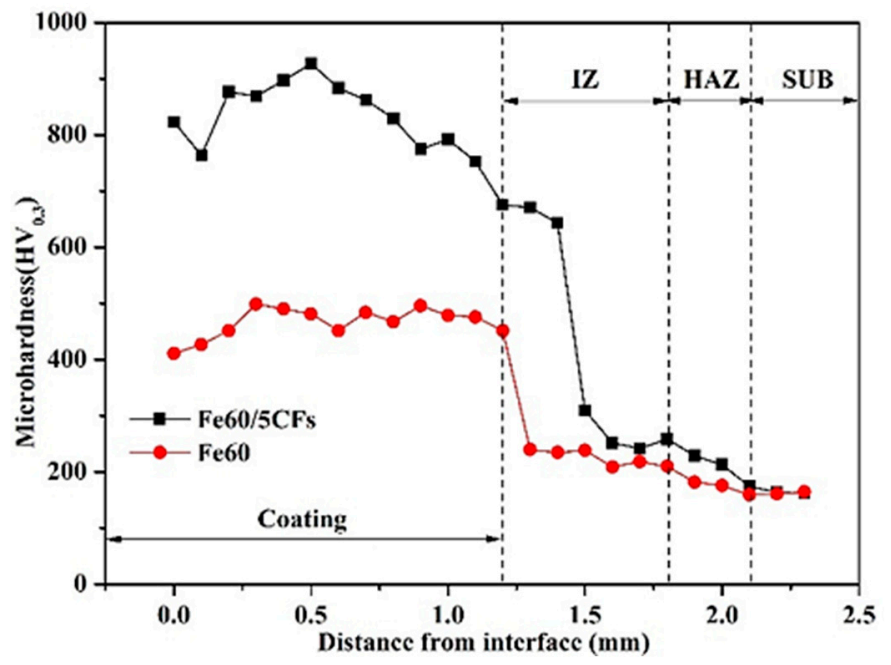

Figure 12. Micro-hardness profile of the transverse cross-section of the composite coatings.

The variations of friction coefficient and wear mass loss of the composite coatings during the dry sliding process are shown in Figure 13. In general, the friction coefficient and the mean wear mass loss rates of Coating 2 were both about 1.5 times as high as that of Coating 1, consistent with the microhardness results. However, it is well known that the relationship between the microhardness and wear resistance is not simply a positive correlation. Thus, it could be inferred that the increased wear resistance of the composite coating with the addition of CFs was not only affected by higher microhardness but also other excellent characteristics.
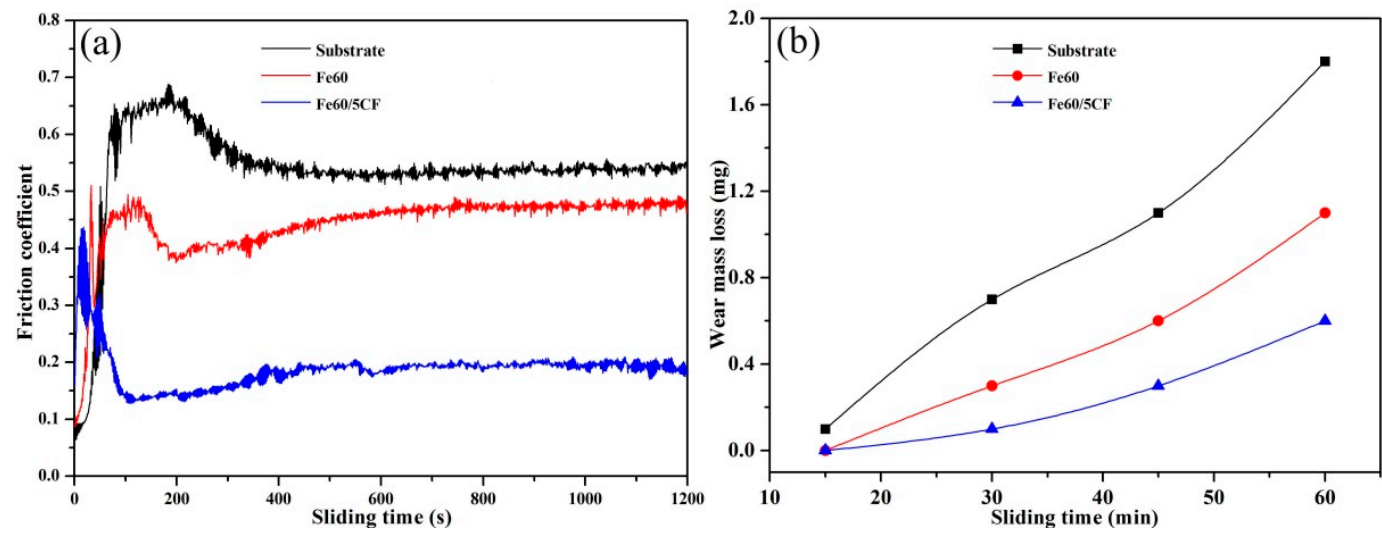

Figure 13. Variations of friction coefficient (a) and wear mass loss (b) of Fe-based composite coatings as a function of time.

\subsection{Wear Mechanism}

The worn surface morphologies were observed in order to reveal their wear mechanisms as shown in Figure 14. There were deep and wide grooves extending parallel to the sliding direction inside the wear scar of Coating 1, derived from the micro-cutting effect of hard micro-bulges on grinding materials [25]. Moreover, when we proceeded with the wear process, work hardening occurred on the worn surface, and brittle spalling would form under repeated shear stress, resulting in the formation of spalling pits. Thus, the dominant wear mechanism of Coating 1 was governed by micro-cutting and serious brittle spalling which well explains the reason why Coating 1 had the higher wear mass loss. 

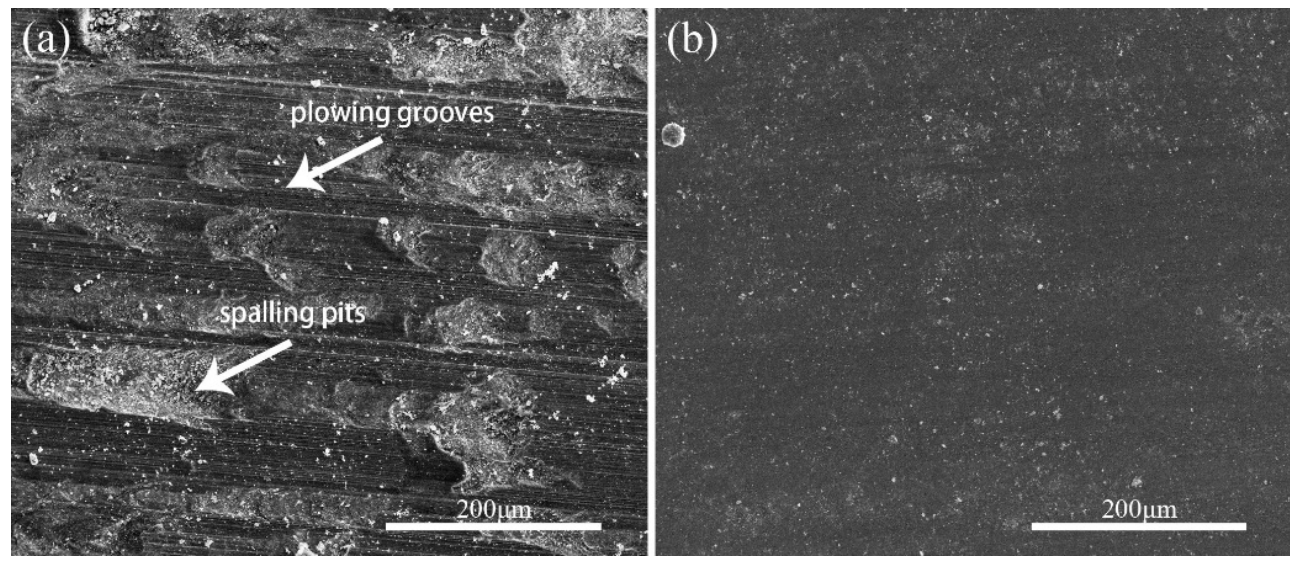

Figure 14. Typical worn surface morphologies of different claddings: (a) Coating 1; (b) Coating 2.

Conversely, the worn surface of Coating 2 was much smoother than that of Coating 1 . The wear mechanism of Coating 2 was slight scratching. The hard phases such as $(\mathrm{Cr}, \mathrm{Fe})_{7} \mathrm{C}_{3}$ and $\mathrm{B}_{4} \mathrm{C}$ could serve as blockade to the micro-cutting when dry sliding with the ceramic counterpart. Moreover, $\mathrm{CFs}$ with good a self-lubricating property could diffuse and accumulate on the rubbing surface to form a tribo-film which would reduce the direct contact areas between the counterpart and the composite coating, further decreasing the friction coefficient and wear mass loss of the composite coatings [26]. In addition, CFs existing in the composite coating like "branches that built nests" should be distributed randomly which could also help to increase the toughness of the coating and decrease the cracking sensitivity. This was the main reason why spalling pits did not occur on the worn surface of Coating 2 .

\section{Conclusions}

In this article, a Fe-based alloy/CF composite coating which was dense and free of defects was fabricated on the surface of $16 \mathrm{Mn}$ steel. The effects of the CFs on the microstructure and wear resistance of the cladding coating were determined. The following conclusions can be drawn.

- Compared with the original Fe-based alloy coating, $(\mathrm{Cr}, \mathrm{Fe})_{7} \mathrm{C}_{3}$ and nano-size $\mathrm{B}_{4} \mathrm{C}$ carbides were in-situ synthesized in the lamellar eutectics' matrix. Moreover, the $\mathrm{CFs}$ were partly dissolved in the melt pool, and the remaining CFs in the composite coating could act as a lubricating phase which contributed to the wear resistance.

- The microhardness of the composite coating was greatly enhanced with the addition of CFs. The hardening mechanism was changed, which transformed from the solid-solution strengthening of supersaturated solid solutions to the dispersion strengthening of in-situ synthesized reinforcements.

- The wear resistance of the composite coating with the addition of CFs was improved by approximately two times compared with the original coating. Wear mechanisms for the composite coating were different. The original coating showed the dominant wear mechanisms of micro-cutting and serious brittle spalling, while the composite coating with CFs showed the main wear mechanism of slight scratching.

Author Contributions: Conceptualization, J.L. and Z.Z.; methodology, J.L. and Z.Z.; software, J.L.; validation, J.L. and Z.Z.; formal analysis, J.L. and Z.Z.; investigation, J.L. and Z.Z.; resources, Z.Z.; data curation, J.L., Z.Z., Y.P. and G.S.; writing-review and editing, J.L., Z.Z., Y.P. and G.S.; supervision, Z.Z., Y.P. and G.S.; project administration, Z.Z.

Funding: This research was supported financially by the Outstanding Innovation Scholarship for Doctoral Candidate of CUMT (2019YCBS030).

Acknowledgments: J.L. wrote the paper. All authors read and approved the manuscript.

Conflicts of Interest: The authors declare no conflict of interest. 


\section{References}

1. da Silva, L.J. NiCrSiBC coatings: Effect of dilution on microstructure and high temperature tribological behavior. Wear 2016, 350-351, 130-140. [CrossRef]

2. Yang, M.S.; Liu, X.B.; Fan, J.W.; He, X.M.; Shi, S.H.; Fu, G.Y.; Wang, M.D.; Chen, S.F. Microstructure and wear behaviors of laser clad $\mathrm{NiCr} / \mathrm{Cr}_{3} \mathrm{C}_{2}-\mathrm{WS}_{2}$ high temperature self-lubricating wear-resistant composite coating. Appl. Surf. Sci. 2012, 258, 3757-3762. [CrossRef]

3. Liu, X.B.; Zheng, C.; Liu, Y.F.; Fan, J.W.; Yang, M.S.; He, X.M.; Wang, M.D.; Yang, H.B.; Qi, L.H. A comparative study of laser cladding high temperature wear-resistant composite coating with the addition of self-lubricating $\mathrm{WS}_{2}$ and $\mathrm{WS}_{2} /(\mathrm{Ni}-\mathrm{P})$ encapsulation. J. Mater. Process. Tech. 2013, 213, 51-58. [CrossRef]

4. Weng, F.; Yu, H.; Chen, C.; Liu, J.; Zhao, L.; Dai, J.; Zhao, Z. Effect of process parameters on the microstructure evolution and wear property of the laser cladding coatings on Ti-6Al-4V alloy. J. Alloys Compd. 2017, 692, 989-996. [CrossRef]

5. Li, M.; Huang, J.; Zhu, Y.Y.; Li, Z.G.; Wu, Y.X. Effect of laser scanning speed on TiN/TiB-Ti based composite. Surf. Eng. 2013, 29, 346-350. [CrossRef]

6. Mahamood, R.M.; Akinlabi, E.T.; Shukla, M.; Pityana, S. Scanning velocity influence on microstructure, microhardness and wear resistance performance of laser deposited Ti6Al4V/TiC composite. Mater. Des. 2013, 50, 656-666. [CrossRef]

7. Fouilland-Paille, L.; Ettaqi, S.; Benayoun, S.; Hantzpergue, J.J. Structural and mechanical characterization of $\mathrm{Ti} / \mathrm{TiC}$ cermet coatings synthesized by laser melting. Surf. Coat. Technol. 1997, 88, 204-211. [CrossRef]

8. Liu, K.; Li, Y.; Wang, J. In-situ synthesized Ni-Zr intermetallic/ceramic reinforced composite coatings on zirconium substrate by high power diode laser. J. Alloys Compd. 2015, 624, 234-240. [CrossRef]

9. Zhang, H.; Zou, Y.; Zou, Z.D. Microstructure and properties of Fe-based composite coating by laser cladding $\mathrm{Fe}-\mathrm{Ti}-\mathrm{V}-\mathrm{Cr}-\mathrm{C}-\mathrm{CeO}_{2}$ powder. Opt. Lasers Eng. 2015, 65, 119-125. [CrossRef]

10. Wang, K.L.; Zhang, Q.B.; Sun, M.L.; Wei, X.G. Microstructural characteristics of laser clad coatings with rare earth metal elements. J. Mater. Eng. Perform. 2003, 139, 448-452. [CrossRef]

11. Han, B.; Li, M.; Wang, Y. Microstructure and wear resistance of laser clad $\mathrm{Fe}_{-} \mathrm{Cr}_{3} \mathrm{C}_{2}$ composite coating on 35CrMo steel. J. Mater. Eng. Perform. 2013, 22, 3749-3754. [CrossRef]

12. Guo, C.; Zhou, J.; Zhao, J.; Chen, J. Effect of $\mathrm{ZrB}_{2}$ on the microstructure and wear resistance of Ni-based composite coating produced on pure Ti by laser cladding. Tribol. Trans. 2011, 54, 80-86. [CrossRef]

13. Yang, Y.; Zhang, D.; Wei, Y. Microstructure and wear properties of TiCN/Ti coatings on titanium alloy by laser cladding. Opt. Lasers Eng. 2010, 48, 119-124. [CrossRef]

14. Zhang, X.R.; Pei, X.Q.; Wang, Q.H. Tribological properties of $\mathrm{MoS}_{2}$ and carbon fiber reinforced polyimide composites. J. Mater. Sci. 2008, 43, 4567-4572. [CrossRef]

15. Savalani, M.M.; Ng, C.C.; Li, Q.H. In situ formation of titanium carbide using titanium and carbon-nanotube powders by laser cladding. Appl. Surf. Sci. 2012, 258, 3173-3177. [CrossRef]

16. Zhou, S.; Wu, C.; Zhang, T. Carbon nanotube- and $\mathrm{Fe}_{\mathrm{p}}$-reinforced copper-matrix composites by laser induction hybrid rapid cladding. Scr. Mater. 2014, 76, 25-28. [CrossRef]

17. Li, R.; Li, Z.; Jian, H. Dilution effect on the formation of amorphous phase in the laser cladded Ni-Fe-B-Si-Nb coatings after laser remelting process. Appl. Surf. Sci. 2012, 258, 7956-7961. [CrossRef]

18. Henrikki, P. Relationship between processing parameters, alloy atom diffusion distance and surface hardness in laser hardening of tool steel. J. Mater. Process. Technol. 2007, 189, 435-440.

19. Zhang, D.; Zhang, X. Laser cladding of stainless steel with $\mathrm{Ni}-\mathrm{Cr}_{3} \mathrm{C}_{2}$ and $\mathrm{Ni}-\mathrm{WC}$ for improving erosive-corrosive wear performance. Surf. Coat. Technol. 2005, 190, 212-217. [CrossRef]

20. Ma, Q.; Li, Y.; Wang, J. Effects of Ti addition on microstructure homogenization and wear resistance of wide-band laser clad Ni60/WC composite coatings. Int. J. Refract. Met. Hard Mater. 2017, 64, 225-233.

21. Nygren, K.; Folkenant, M.; Jansson, U. Influence of nanoeffects on the oxidation of Cr-C/Ag thin films containing silver nanoparticles. ChemElectroChem 2017, 4, 418-429. [CrossRef]

22. Xu, J.; Liu, X.; Wang, S. A novel 3D network nanostructure constructed by single-crystal nanosheets of $B_{4} C$. Ceram. Int. 2017, 43, 16787-16791. [CrossRef]

23. Lei, J.; Shi, C.; Zhou, S. Enhanced corrosion and wear resistance properties of carbon fiber reinforced Ni-based composite coating by laser cladding. Surf. Coat. Technol. 2018, 334, 274-285. [CrossRef] 
24. Liu, K.; Li, Y.; Wang, J. Effect of high dilution on the in situ synthesis of $\mathrm{Ni}-\mathrm{Zr} / \mathrm{Zr}-\mathrm{Si}(\mathrm{B}, \mathrm{C})$ reinforced composite coating on zirconium alloy substrate by laser cladding. Mater. Des. 2015, 87, 66-74. [CrossRef]

25. Li, J.; Chen, C.; Squartini, T.; He, Q. A study on wear resistance and microcrack of the $\mathrm{Ti}_{3} \mathrm{Al} / \mathrm{TiAl}+\mathrm{TiC}$ ceramic layer deposited by laser cladding on Ti-6Al-4V alloy. Appl. Surf. Sci. 2010, 257, 1550-1555. [CrossRef]

26. Tang, Y.; Liu, H.; Zhao, H. Friction and wear properties of copper matrix composites reinforced with short carbon fibers. Mater. Des. 2008, 29, 257-261. [CrossRef]

(C) 2019 by the authors. Licensee MDPI, Basel, Switzerland. This article is an open access article distributed under the terms and conditions of the Creative Commons Attribution (CC BY) license (http://creativecommons.org/licenses/by/4.0/). 